\title{
The influence factors of private capital to participate in old-age service facilities and countermeasure research
}

\author{
Hua Liu ${ }^{1, a}$, Xuechao Xie ${ }^{2, b}$ \\ ${ }^{1}$ Xi'an University of Architecture and Technology , Xi'an 710055, China; \\ ${ }^{2}$ Xi'an University of Architecture and Technology, Xi'an 710055, China. \\ alhxjd@foxmail.com, ${ }^{b} 1017739099 @ q q . c o m$
}

Keywords: the private capital ; the pension service facilities; factors ; countermeasures;suggestions.

\begin{abstract}
Now our country has gone into the era of serious aging population,as the elderly population increasing year by year, the pension service facilities for the elderly in terms of quantity and quality of serious deficiencies.but our existing private capital amount is huge, the private capital invest the pension service facilities, promoting the development of China's old-age service facilities is of great significance.This paper is explicitly dedicated to find the private capital participation in pension service facilities construction factors, Meanwhile putting forward to promoting the private capital participation in pension service facilities related countermeasures and suggestions.
\end{abstract}

\section{Introduction}

According to China's sixth census results: in 2010 aged 60 and above population had reached 178 million, accounting for $13.26 \%$ of the population, up $2.93 \%$ than the fifth population census in $2000^{[1]}$.Due to the aging- society in our country has a large population base, aging trend, the elderly population growth accelerated obviously, old before rich and "421" family structure and other characteristics, by 2050, the number of elderly people aged 60 and above in our country will be more than $30 \%$, the ratio of population has far more than the international definition of an aging society, China will enter a depth of aging stage.China has entered an aging society seriously, as the elderly population increasing year by year, but the number of pension service facilities for elderly population and species increase is not obvious, there are deficiencies in all aspects.

Facing of the increasing number of elderly people, the problem which increases pension service facilities construction is the need to solve .But our country folk capital (through savings index), from the beginning of reform and opening up in 1978, our country residents savings amount is 21.06 billion, and 30 years later, in 2008, the number has reached 21.4 trillion ,growing nearly one thousand times.By the end of 2014, the number has reached more than 48 trillion (figure 1), that doesn't include residents armed with cash and securities. Therefore, our country folk capital amount is quite huge.As the population aging phenomenon becomes more and more serious in our country, the government financial investment in the construction of old-age service facilities cannot satisfy the more and more old people actual demand, the government issued some relevant policy documents to encourage private capital to participate in the pension service facilities in the field of construction is undoubtedly one of the best decisions to solve the problem. On the one hand, it can play a role in the folk capital in market economy produce economic benefits, making investors get some benefits; On the other hand, can also alleviate the pressure of the government finance, improving the investment efficiency.But ,at present ,a lot of folk capital investors to old-age service facilities areas always holds a waiting attitude.To this, this article analyzes the present situation of private capital to participate in old-age service facilities, clearing the influence factors of private capital to participate in old-age service facilities, and putting forward to relevant countermeasures and suggestions. 


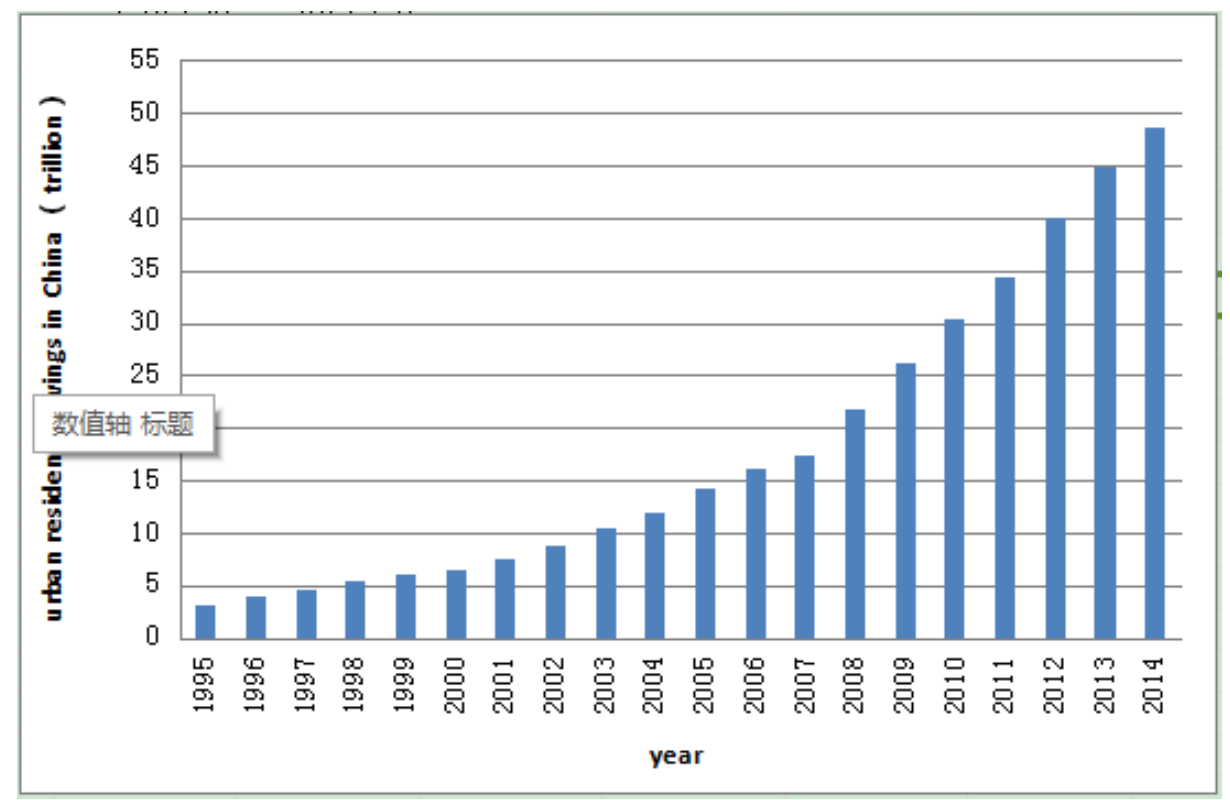

figure 1. savings for urban residents in China from 1995 to 2014 years

\section{Theoretical basis and the present condition of the folk capital to participate in old-age service facilities}

2.1Private capital and pension services definition

Private capital,mainly to distinguish from the viewpoint of ownership in state-owned capital and foreign capital,refers to a country or a region within the sum of non-state capital and foreign capital.It is mastered in private and joint-stock enterprise owned by the private equity and other forms of private capital.In our country, there is no unified definition of private capital.According to the

regulation of the zhejiang statistics yearbook 2004,Private capital is the capital of non-governmental finance owns.As defined in this paper, the scope of private capital ${ }^{[2-3]}$.

Pension service facilities for the elderly (above 60) is life care, social care and other integrated services.It mainly contains welfare homes, nursing homes, elderly care, nursing home, elderly apartments,and senior housing.Such as elderly, the elderly activity center at the university of involving the elderly life and provide comprehensive service facilities.

2.2 The present situation in the construction of old-age service facilities

Community is an important to rely for old people to spend their twilight years, and in the community endowment service facilities construction is closely related to the improvement of the living environment quality in the elderly ${ }^{[3]}$.At present, There are many problems in China's old-age service facilities.

(1) Community endowment service facilities is unitary, and the type is also not

complete.Although, the communities have built many elderly service facilities, such as age and elderly apartment, nursing homes, care of the restaurant and so on.The kinds of pension service facilities are too little.As the elderly population increases gradually, the old people to the requirement of health care and nursing, etc will be increased significantly.Meanwhile,the elderly themselves for life style, to participate in social development and social requirement is also increasing day by day.So, current pension services is short supply, and it also has the very big promotion space ${ }^{[3]}$.

(2) Serious shortage of beds.For example, in Beijing,by the end of 2009, it is a total of 366 various types of social endowment facilities in the city and a total of 39994 beds. Every one hundred people occupies 1.6 beds on average.And this level with developed countries on average every one hundred elderly occupies 5-7 beds level also has the very big disparity ${ }^{[4]}$.

(3) Endowment facilities service level is not high.Pension agency service standards depends on many factors such as facilities, management and service level, service attitude and supporting function, etc.Pension agency overall occupancy is low , mainly because of the poor pension agency 
So, according to the present situation of old-age service facilities in China, it is very necessary to introduce private capital to participate in old-age service facilities. On one hand, it can alleviate funding by the government pension service facilities construction pressure, increasing the utilization of funds.On the other hand ,it can solve the present types of single pension service facilities, the uncomplete category, endowment beds and the inadequate endowment low service level problems.

\section{Private capital to participate in old-age service facilities impact factor analysis}

Though, a considerable amount of folk capital in our country at present, but for the private capital participation in investment old-age service facilities are not positive.There are several factors lead to this phenomenon.

3.1 Laws and regulations and policy environment

(1) Private capital to participate in old-age service facilities imperfect laws and regulations.For private capital to participate in old-age service facilities construction of the relevant laws and regulations or blank, no specific law enforcement rules for protection.Private investors or concerned ,dare not rashly investment no legal protection areas.

(2) The government issued some policies of strong principle, which is difficult to implement. The related preferential policy implementation does not reach the designated position.The ministry of civil affairs issued relevant preferential policies.But the reality is lots of private pension institutions water, electricity, gas, heat is not the same price, with households still the same as the enterprise of water, electricity, gas, heat related standards.Some private pension agency the adopted land policy is not allocated.So,Some policy still stays in the text,which is not in place ${ }^{[6]}$.

3.2 Determined by the pension service facilities itself attribute

(1) Large investment and high operating costs.Prior to the construction of the endowment facilities need to invest much money.Although our country folk capital amount is considerable, if only personal power invest to build these constructions such as the welfare homes, nursing homes, elderly care, nursing home, elderly apartments, senior housing,etc which is hard to finish. The pension service facilities which are welfare or public welfare, to stay in charge for low-income elderly people generally is not high, this endowment facilities in the process of business operating costs will be very high, leading to private investors who are interested to invest old-age service facilities.

(2) Long payback period and low return rate.Described above pension service facilities in addition to the big initial investment and medium high operating costs, there are folk capital investment of the construction of the endowment services and investment long recovery and low return rate characteristics.According to the Beijing some private nursing home observer, private nursing home investment payback period is generally long, usually in 10 to 15 years, and the investment yield from $8 \%$ to $10 \%{ }^{[7]}$.In fact, long payback period and returning the characteristics of low interest rates are reluctant to participate in one of the leading causes of old-age service facilities for private capital.

\section{Countermeasures and Suggestions}

(1) Perfecting the folk capital to participate in old-age service facilities in the field of related legal administrative rules and regulations.Ensure that private capital to participate in old-age service facilities there are specific rules and regulations as the guarantee, making no scruples of folk capital to participate in the pension service facilities construction and promoting development of pension services in China.

(2) Government purchase services. If private investors don't want to continue to operate, the government can directly purchase service management from private investors to buy back.Managing operations old-age service facilities by the relevant government departments.It can avoid private investors in the insufficient funds in the process of operation and the potential risk problems.

(3) Clearing the land use properties.In the process of folk capital invest to the old-age service facilities ,Clearing the land use properties have been investors one of the most concerned problems.Government should publish relevant policy clear as soon as possible the folk capital invest 
to the construction old-age service facilities construction land properties.Try-ing to make the folk capital to participate in old-age service facilities construction land and nonprofit endowment agencies obtain land price.

\section{References}

[1] LiBin, the current situation ,problems and strategies of elderly facilities in China[J].Time Architecture,vol.145,June,2012,pp 11-14.

[2] ZhangXiaoqin, Private capital development research in our country[D]. Shanghai:East China Normal University,2009 .

[3] JiFengxiang,The concept of private capital and the statistical method[J].Beijing Statistics,vol. 153, Nov. 2002, pp. 39-40.

[4] ZhangYan.Under the background of rapid aging community endowment service facilities construction---in Suzhou as an example[J].Journal of hunan college of finance and economics,vol. 125, Sep. 2010, pp. 24-26.

[5] ChenZhe,WangHuijun,ChenWei.Beijing social endowment facilities survey and research[J].Uban Planning,vol. 132, Dec. 2013, pp. 52-53.

[6] LiZhanwu.Beijing endowment facilities construction of six major problems need to be solved[J].Beijing academy of social sciences,vol. 128, June. 2011, pp. 56-60.

[7] HuangBin.Expansion of private pension institutions,"Monopoly" distort the market price[N].the 21st century economic report,Sep,2014. 